\title{
Young's Modulus and Degree of Conversion of Different Combination of Light-Cure Dental Resins
}

\author{
Emami $\mathrm{N}^{1, *}$ and Söderholm $\mathrm{KJ}^{2}$ \\ ${ }^{I}$ Department of Applied Physics and Mechanical Engineerings, Luleå University of Technology, SE-971 87 Luleå, \\ Sweden \\ ${ }^{2}$ Department of Dental Biomaterials, College of Dentistry, University of Florida, Gainesville FL 32610-0446 USA
}

\begin{abstract}
Objectives: To evaluate Young's modulus and degree of conversion of several combinations of bisGMA, UEDMA, TEGDMA light-cure dental resin.

Methods: Young's modulus and DC\% were studied for 21 different resin combinations of bisGMA, TEGDMA and UEDMA. Small universal testing machine and photo-calorimetry were used for the tests. The results were evaluated using ANOVA and Duncan's multiple range tests and regular t-test.

Results: Young's modulus varied between $2.37 \pm 0.2 \mathrm{GPa}(100 \%$ TEGDMA) and 4.15 $\pm 0.2 \mathrm{GPa}$ (100\% bisGMA). By adding TEGDMA to bisGMA or UEDMA, the Young's modulus decreased significantly ( $<<0.05)$. Degree of conversion was significantly $(\mathrm{p}<0.05)$ higher when the wt $\%$ of TEGDMA was high in the mixtures than for highly concentrated bis-GMA (resin mixtures with TEGDMA in comparison to mixture with bisGMA had higher degree of conversion). DC\% was significantly higher $(\mathrm{p}<0.05)$ for binary mixtures of UEDMA and TEGDMA, and significantly lower for 100 wt $\%$ bis-GMA $(\mathrm{p}<0.05)$. The DC\% values were between $53.1 \% \pm 0.9 \%$ (100\% bisGMA) and $85.6 \% \pm 1 \%$ (80\% UEDMA-20\% TEGDMA). The concentration of bisGMA, in the monomer mixture, affected DC\% and Young's modulus oppositely.

Conclusions: The differences in the values for DC\% were mostly justified by the differences in the molecular structures of the different monomers. It was also revealed that higher DC\% does not always result in a higher Young's modulus, because molecular and network structural parameters play major roles in the final physical properties of the mixtures.
\end{abstract}

\section{INTRODUCTION}

A potential problem with dental composite resins is incomplete polymerization which can result in poor mechanical properties. It is therefore important to identify the optimum resin combination(s) that result in high polymerization level and good mechanical properties.

Degree of conversion (DC) is used to determine polymerization level of dental composite resins [1-3], and is related to mechanical properties [4], biocompatibility [5], colour stability [6]. DC is also believed to be related to the clinical performance of the restoration. It is therefore important to identify the best monomer combinations capable of producing high degree of conversion and good mechanical properties of visible light cure dental (VLCD) composite resins.

Many methods can be used to measure the degree of conversion, and the percentage of consumed aliphatic carbon double bonds during polymerization are often used to express the DC value. Some of the most common methods that have been used are nuclear magnetic resonance spectroscopy [7,8], differential scanning calorimetry [9-18], Raman spectroscopy [19,20], conventional infrared spectroscopy [21-25] and Fourier transform infrared spectroscopy (FTIR) [26-31].

*Address correspondence to this author at the Department of Applied Physics and Mechanical Engineerings, Luleå University of Technology, SE-971 87 Luleå, Sweden; Tel: +46-920-491939; Fax: +46-920-491399; E-mail: nazanin.emami@ltu.se
Light cure dental composites typically show limited conversion values, and the conversion values range between 40 to 80 percent $[9,20,23-25,29]$. The low conversion values can be related to the cross-linked polymer network structure that imposes severe restrictions on the mobility of reacting species. To improve conversion, diluents with viscosities up to five orders of magnitude lower than that of a resin like bisGMA are usually used. These diluents are added to facilitate filler addition and mixing. Both the improved conversion level and the increased filler fraction contribute to improving the mechanical properties of the composite. The increased molecular mobility caused by the incorporation of diluents can increase the conversion level 2.5 times over that of pure bisGMA (from $26 \%$ for pure bisGMA to $66 \%$ for 50/50 bisGMA/TEGDMA) [32]. Structural differences within the diluents contribute to variations in conversion because of differences in segmental motion of the methacrylate groups [33]. However, differences in properties of different methacrylate based matrices complicate the interpretation of correlations between conversion and mechanical properties of VLCD composites. For example, by increasing the concentration of TEGDMA mixed with bisGMA, the measured flexural strength decreases despite of an increase in conversion [34,35].

Dental light cure resin composites consist of differently processed filler particles mixed with different monomer systems. Monomer system consisting of bisphenol A glycerolate (1 glycerol/phenol) dimethacrylate/tri[ethylene glycol] di- 
Table 1. Materials Used in the Study

\begin{tabular}{|c|c|c|c|}
\hline Material & Abbreviation & Source & Batch. No. \\
\hline $\begin{array}{l}\text { Bisphenol A glycerolate (1 glycerol/phenol) di- } \\
\text { methacrylate }\end{array}$ & bisGMA & \multirow{2}{*}{$\begin{array}{l}\text { Aldrich Chemical Company,Inc } \\
\text { Milwaukee WI 53233, USA }\end{array}$} & 06703DO \\
\hline Diurethane dimethacrylate, mixture of isomers & UEDMA & & $12319 \mathrm{TG}$ \\
\hline Tri(ethylene glycol) dimethacrylate, $95 \%$ & TEGDMA & \multirow{3}{*}{$\begin{array}{c}\text { Sigma-Aldrich Chemie GmbH } \\
\text { Riederstr. 2, D-89555 Stenheim- Germany }\end{array}$} & 07908DQ-081 \\
\hline Camphorquinone & CQ & & $12.489-3$ \\
\hline 2(Dimethyllamino)ethylmethacrylate, $98 \%$ & DMAEMA & & BO05923KU \\
\hline
\end{tabular}

methacrylate (bisGMA/TEGDMA), 50:50 by weight, has been used in some products. The high viscosity of bisGMA slows down filler sedimentation in the composite and gives the material a firmer touch. A drawback with the high viscosity, though, is that it makes filler incorporation more cumbersome. In addition, the structure of the bisGMA molecules makes the molecule stiff, which decreases the conversion level of the monomer as the bisGMA content increases. To decrease monomer viscosity, facilitate filler incorporation and enhance degree of conversion, a diluting monomer such as TEGDMA is added. A shortcoming with adding TEGDMA is that the shorter molecule and its higher conversion level increase the polymerisation shrinkage of the matrix. Because of the lower viscosity, though, the increased shrinkage can to some extent be compensated by increased filler incorporation. However, to decrease shrinkage, and still retain good conversion, some manufacturers add UEDMA to the bisGMA/TEGDMA mixture. UEDMA is a more flexible molecule than the bisGMA molecule and cures more efficiently than bisGMA. It also has lower viscosity than bisGMA, making filler incorporation easier. However, despite these advantages, UEDMA has not been able to replace bisGMA completely. The reason is that UEDMA based resins do not have the same handling characteristics as a matching bisGMA system.

Because of the importance of identifying a monomer mixture with low viscosity and low shrinkage but also high conversion, we need to identify the bisGMA:UEDMA: TEGDMA combination that produces the superior matrix material in terms of high conversion levels and high stiffness within acceptable viscosity ranges. Therefore, the objective with this study was to evaluate Young's modulus and degree of conversion of several combinations of light-cure dental resins e.g., bisGMA, UEDMA, TEGDMA.

\section{MATERIALS AND METHODS}

Material groups: In Table 1 materials used in this study are shown. To make the resin matrices light curable, photo initiator (camphorquinone $0.35 \mathrm{wt} \%$ ) and coinitiator (dimethylaminoethylmethacrylate (DMAEMA) $0.7 \mathrm{wt} \%$ ) were added to the monomer mixtures. Twenty-one different resin combinations from the tertiary bisGMA:TEGDMA:UEDMA system were prepared (the weight $\%$ of monomers in different mixtures are shown in Tables $\mathbf{2}$ and $\mathbf{3}$ ).

Tensile test specimens: For the tensile test, 6 specimens per resin formulation were prepared.
To ease the handling of the prepared mixtures, all 21 formulations were preheated at $37{ }^{\circ} \mathrm{C}$ for

$30 \mathrm{~min}$ before they were carefully poured into Teflon mould to produce samples $50 \mathrm{~mm}$ long, $8 \mathrm{~mm}$ wide and 1 $\mathrm{mm}$ thick. Once the mould had been filled and covered with Mylar sheets, a weight was placed on the covered mould to compress the liquid and secure proper shape and thickness. The weigh was then removed after $15 \mathrm{~s}$ and specimen was cured with Osram Dulux laboratory curing (manufactured in Italy) unit with $30 \mathrm{~mW} / \mathrm{cm}^{2}$ for $10 \mathrm{~min}$. After the specimens had been removed form the mould their sides were polished flat under water with a SiC sand paper (P 600). Specimens made in this way were then stored in darkness for 24 before they were tested.

Tensile testing procedure: Strain gauges (Student gauge type CEA-06-240UZ-120; Measurements Group, Inc., Raleigh, NC, USA) were attached to the specimens at least 24 hours before the test was conducted. Minimat (Model MM11-04, Thermal Sciences, Loughborough, England) was used for Young's modulus measurement and the specimens were tested in tension at a strain rate of $1 \%$ per min. The elastic modulus of each specimen was calculated by measuring the slope of the stress-strain curve between 0.05 and $0.25 \%$ of strain.

Degree of conversion: The percentage of aliphatic carbon double bonds reacting during polymerization of the matrix resins were used to measure the degree of conversion. Photocalorimetry (photo-DSC) was used for these measurements. Photo-DSC is based on isothermal differential scanning calorimetry (DSC), which measures the amount of heat released during polymerization. Some of the recorded heat generated during photo-DSC measurement is heat released by the light curing source. The heat generated by the light source is subtracted from the total heat being released during curing, and the resulting heat represents the amount of heat released during curing. By using the energy value released by one mole aliphatic bonds during curing, one can calculate how many percentages of the aliphatic bonds have participated in the polymerization reaction [36].

In isothermal methods, the rate of heat evolution and the reaction rate are recorded as a function of irradiation time. The rate of polymerization $\left(R_{p}\right)$, i.e. the rate of monomer conversion is given by:

$$
R_{p}=-\frac{d[M]}{d t}=\frac{d H}{d t} * \frac{1}{V \Delta H_{0}}
$$


Table 2. Young's Modulus with Standard Deviation and Waller Grouping for All Mixtures (Shown Number is Mean Values of Six Measurements)

\begin{tabular}{|c|c|c|c|c|c|}
\hline Mixture (No.) & bisGMA (\% wt) & UEDMA (\% wt) & TEGDMA (\% wt) & E-modulus (GPa) & Waller Grouping \\
\hline 1 & 100 & 0 & 0 & $4.1 \pm 0.5$ & A \\
\hline 3 & 0 & 0 & 100 & $2.4 \pm 0.3$ & I \\
\hline 4 & 80 & 20 & 0 & $3.2 \pm 0.6$ & CDEFG \\
\hline 6 & 40 & 60 & 0 & $3.1 \pm 0.6$ & DEFG \\
\hline 7 & 20 & 80 & 0 & $3.6 \pm 0.9$ & $\mathrm{ABCD}$ \\
\hline 8 & 0 & 20 & 80 & $2.5 \pm 0.5$ & $\mathrm{HI}$ \\
\hline 12 & 80 & 0 & 20 & $4.2 \pm 0.8$ & A \\
\hline 13 & 60 & 0 & 40 & $3.4 \pm 0.7$ & BCDEF \\
\hline 14 & 40 & 0 & 60 & $3.2 \pm 0.6$ & DEFG \\
\hline 15 & 20 & 0 & 80 & $3 \pm 0.3$ & EFGHI \\
\hline 16 & 20 & 20 & 60 & $3.3 \pm 0.6$ & CDEFG \\
\hline 17 & 40 & 20 & 40 & $3.8 \pm 0.6$ & $\mathrm{ABC}$ \\
\hline 18 & 60 & 20 & 20 & $3.8 \pm 0.8$ & $\mathrm{AB}$ \\
\hline
\end{tabular}

$\mathrm{dH} / \mathrm{dt}$ is the ordinate of the curve $(\mathrm{J} / \mathrm{s}), \Delta \mathrm{H}_{\mathrm{o}}$ is the molar heat of polymerization $(\mathrm{J} / \mathrm{mol})$ (based on the full conversion monomer), $\mathrm{V}$ is the total reaction volume $(\mathrm{L})$, and $[\mathrm{M}]$ is the monomer concentration $(\mathrm{mol} / \mathrm{L})$. This equation ignores the heat produced by the decomposition of the photo-initiator and the termination reactions.

Assuming that the heat evolved in DSC measurement is proportional to the number of monomer moles reacted, the degree of monomer conversion $(\alpha)$ as a function of time $(t)$ can be calculated from:

$$
\alpha=\frac{\Delta H}{\Delta H_{0}} * 100
$$

Statistical analysis: The results were tested using ANOVA and Duncan's multiple range tests and regular ttest. All tests were performed at the $\mathrm{p}<0.05$ level.

\section{RESULTS}

Youngs modulus: The moduli of elasticity values, measured 24 hours after the samples had been cured, are shown in Fig. (1). The standard deviation and Waller groupings are also shown in Table 2. Statistical evaluation of the data revealed that the modulus of elasticity was significantly higher for pure bisGMA than pure TEGDMA and pure UEDMA. The statistical evaluation also revealed that different combination of three resins did not affect the modulus of the mixture significantly. As seen from Table 2, Youngs' modulus values vary between 2.37 (for 100\% TEGDMA) and 4.15GPa (for $100 \%$ bisGMA).

Degree of conversion: Fig. (2) shows degree of conversion values calculated for the cured 21 mixtures. The Waller groupings are also shown in that table. There were significant differences between degree of conversions of the pure resins $(\mathrm{p}<0.05)$. Increased amounts of bisGMA always affected the degree of conversion adversely. Pure TEGDMA showed significantly higher degree of polymerization, as well faster polymerization rate. Values going from $53.1 \%$ (for $100 \%$ bisGMA) to $85.6 \%$ (for $80 \%$ UEDMA and $20 \%$ TEGDMA) of conversion are found. The higher the mixture contents of bisGMA, the lower the degree of conversion while higher concentrations of TEGDMA gave higher degree of conversion values. The presence of UEDMA played an intermediate role between the two monomers, giving usu- 
Table 3. Degree of Conversion with Standard Deviation and Waller Group for All Mixtures (Shown Number is Mean Values of Six Measurements)

\begin{tabular}{|c|c|c|c|c|c|}
\hline Mixture (No.) & bisGMA (\% wt) & UEDMA (\% wt) & TEGDMA (\% wt) & $\mathrm{DC}(\%)$ & Waller Grouping \\
\hline 1 & 100 & 0 & 0 & $53.1 \pm 7$ & $\mathrm{~J}$ \\
\hline 2 & 0 & 100 & 0 & $74 \pm 3.8$ & EFG \\
\hline 3 & 0 & 0 & 100 & $83.6 \pm 3.1$ & $\mathrm{AB}$ \\
\hline 4 & 80 & 20 & 0 & $62.2 \pm 5.9$ & I \\
\hline 5 & 60 & 40 & 0 & $68.1 \pm 7.7$ & GHI \\
\hline 6 & 40 & 60 & 0 & $70.4 \pm 4.2$ & FGH \\
\hline 7 & 20 & 80 & 0 & $78.9 \pm 2.9$ & $\mathrm{BCDE}$ \\
\hline 8 & 0 & 20 & 80 & $82.9 \pm 4.3$ & $\mathrm{ABC}$ \\
\hline 9 & 0 & 40 & 60 & $76.7 \pm 3.2$ & $\mathrm{CDEF}$ \\
\hline 10 & 0 & 60 & 40 & $85.5 \pm 2.3$ & A \\
\hline 11 & 0 & 80 & 20 & $85.6 \pm 7.1$ & A \\
\hline 12 & 80 & 0 & 20 & $71.9 \pm 3.3$ & FGH \\
\hline 13 & 60 & 0 & 40 & $78.3 \pm 5.3$ & $\mathrm{BCDE}$ \\
\hline 14 & 40 & 0 & 60 & $80.4 \pm 2.8$ & $\mathrm{ABCD}$ \\
\hline 15 & 20 & 0 & 80 & $80.4 \pm 8.1$ & $\mathrm{ABCD}$ \\
\hline 16 & 20 & 20 & 60 & $75.2 \pm 8.9$ & DEF \\
\hline 17 & 40 & 20 & 40 & $72.6 \pm 6.5$ & EFGH \\
\hline 18 & 60 & 20 & 20 & $67.4 \pm 9.8$ & HI \\
\hline 19 & 20 & 40 & 40 & $82.1 \pm 5.8$ & $\mathrm{ABC}$ \\
\hline 20 & 40 & 40 & 20 & $75.2 \pm 8.7$ & DEF \\
\hline 21 & 20 & 60 & 20 & $76.7 \pm 4.9$ & $\mathrm{CDEF}$ \\
\hline
\end{tabular}

ally degrees of conversion higher than the bisGMA and lower than the TEGDEMA.

\section{DISCUSSION}

The structural features of the three monomer molecules can explain the modulus results. Of the three monomers, the bisGMA molecule has the least flexible molecular structure because of the two aromatic rings present along the backbone structure. In addition, the chains are also held together by hydrogen bonds formed between pendant $\mathrm{OH}$ groups. The molecular stiffness and the hydrogen bond formation are important factors to consider [34,37].

Both the UEDMA and the TEGDMA molecules are more flexible than the bisGMA molecule. The TEGDMA molecule is also significant shorter than bisGMA. Both the bisGMA and the UEDMA molecules have hydrogen bonds, but the higher rigidity of the bisGMA molecule, caused by the presence of the two phenol rings, increases the likelihood of stable hydrogen bond formation of the bisGMA monomer when compared to the more flexible UEDMA molecule. The higher flexibility and ability of chain rotations of both TEGDMA and UEDMA molecules and their lower tendencies of forming stable hydrogen bonds should decrease the rigidity of such polymers. As shown in Fig. (1), the Young's modulus also increased as the concentration of the bisGMA increased in the monomers' mixtures [20].

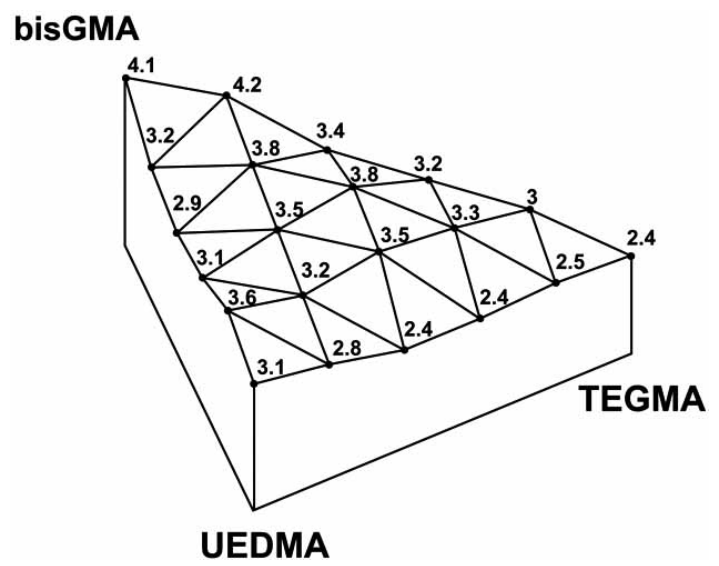

Fig. (1). Graph showing the modulus values of the different material mixtures. The unit for the modulus is Gpa. 
The molecular differences discussed above should also facilitate diffusion of light initiator/co-initiator and increase chain rotations in TEGDMA and UEDMA monomer systems. As a consequence of the increased chain rotation ability, the chance that methylmethacrylate groups react with each other during polymerization should increase. By considering the molecular structures, TEGDMA would be the structure having the highest ability to rotate, move and polymerize and thereby also react easiest. As a consequence, increased TEGDMA should favor an increase in DC. These expectations are also supported by the results presented in Fig. (2) and Table 3.

\section{bisGMA}

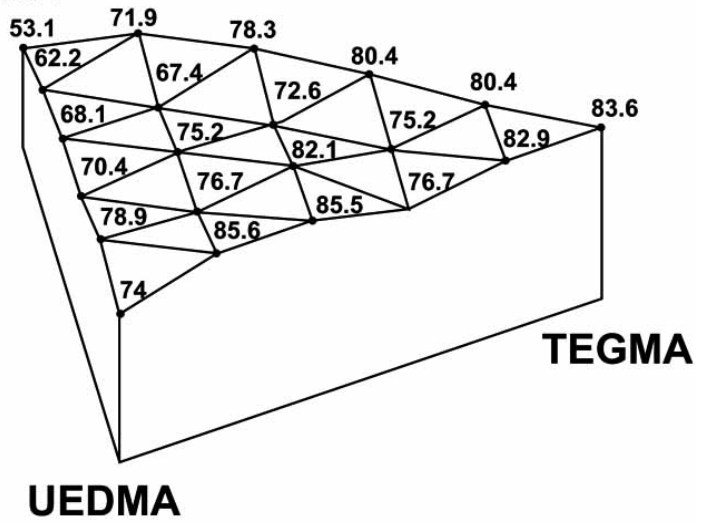

Fig. (2). Graph showing the conversion values for the different material mixtures. The conversion values numbers are shown as mean values with their standard deviations. The unit for the conversion level is \% consumed (polymerized) methacrylate groups.

For higher concentrations of bisGMA, the strong impact of stiffness and hydrogen bond formation ability can explain why the modulus increases (Fig. 1) despite a decrease in conversion (Fig. 2). The low modulus value at higher concentration of TEGDMA may also be due to that block and/or random polymerization units of bisGMA/TEGDMA form. In such polymers, some of the TEGDMA may not be able to cross-link, because the longer bisGMA molecules keep the growing chains too far apart to allow cross-linkage with the shorter TEGDMA molecules. However, as such a copolymer forms, the bisGMA molecules will be separated from TEGDMA molecules, a separation that will decrease the contribution from hydrogen bond formation between bisGMA molecules. Under such a situation, the stiffness of the polymer should go down and reach a minimum.

Among the bisGMA/TEGDMA combinations, the modulus was highest at $100 \%$ bisGMA, and lowest at $100 \%$ TEGDMA, while the conversion level much lower for the $100 \%$ bisGMA than for $100 \%$ TEGDMA. In general, the results suggest that the degree of conversion values increased as the TEGDMA and UEDMA content increased while it decreased as the bisGMA content increased.

By comparing the DC values and the modulus values of the UEDMA/TEGDMA mixtures one can see that the mixtures with highest UEDMA values have high modulus and lower DC values. The higher modulus values can be related to the ability of the UEDMA molecules to form hydrogen bonds, while the increased flexibility of the TEGDMA molecules increases the conversion level.

The differences found between modulus and DC values seen for the rest of the bisGMA/UEDMA/TEGDMA resins can be explained in the same way. Thus, it seems as the highest modulus can be achieved when hydrogen bonding and conversion level are maximized. However, because hydrogen bonding and molecular stiffness increase viscosity and decrease conversion, these processes compete with each other. These findings are important to realize, because they clearly show that high modulus values may not be related to high conversion levels.

\section{CONCLUSIONS}

Even though there is some correlation between Young's modulus and degree of conversion, a high Young's modulus value does not always mean a high conversion level. The reason such a correlation is not always reliable can be related to the molecular structure of the monomer system and how it affects the polymer network. Therefore, to optimize modulus and conversion level, it is important to identify the best monomer combinations. An optimal combination is one that reduces the residual stress level by decreasing polymerization rate. At the same time, the optimal combination will keep stiffness and degree of conversion at acceptable levels in order to give acceptable mechanical/physical properties of the cured composite.

\section{ACKNOWLEDGMENT}

Authors would like to acknowledge that the mat-lab calculations and 3-D images of the results were developed in MATLAB with help of Dr. Anderas Almqvist (department of applied physics and mechanical engineering, Luleå University of Technology, Sweden).

\section{REFERENCES}

[1] Rueggeberg FA, Caughman WF, Curtis JW Jr, Davis HC. Factors affecting cure at depths within light-activated resin composites. Am J Dent 1993; 6: 91-5

[2] Rueggeberg FA, Caughman WF, Curtis JW Jr. Effect of light intensity and exposure duration on cure of resin composite. Oper Dent 1994; 19: 26-32.

[3] Nomoto R, Uchida K, Hirasawa T. Effect of light intensity on polymerization of light-cured composite resins. Dental Mater 1994; 13: 198-205.

[4] Ferracane JL, Greener EH. The effect of resin formulation on the degree of conversion and mechanical properties of dental restorative resins. J Biomed Mat Res 1986; 20: 121-131.

[5] Geurtsen W, Leyhausen G. Chemical-biological interactions of the resin monomer triethyleneglycol-dimethacrylate (TEGDMA). J Dent Res 2001; 80: 2046-50.

[6] Taira M, Wakasa K, Yamaki M, Tanaka N, Shintani H. Cutting effectiveness and wear of carbide burs on eight machinable ceramics and bovine dentin. Dent Mater J 1991; 7: 247-53.

[7] Lloyd CH, Scrimgeour SN, Chudek JA, et al. Determination of the depth of cure for VLC composites by nuclear magnetic resonance micro imaging. Dent Mater 1994; 10: 128-33.

[8] Heatley F, Yosthawee P, Mchugh N, Watts DC, Devlin H. Determination of extent of reaction in dimethacrylate-based dental composites using solid-state ${ }^{13} \mathrm{C}$ m.a.s. n.m.r. spectroscopy and comparison with FTi.r. spectroscopy. Polymer 1995; 36: 1859-67.

[9] Maffezzoli A, Terzi R, Nicolais L. Cure behaviour of visible light activated dental composites. Part I and II. J Mater Sci Mater Med 1995; 6: 155-66.

[10] Abadie MJ, Appelt BK. Photocalorimetry of light-cured dental composites. Dent Mater 1989; 5: 6-9 
[11] Cook WD. Kinetics and properties of a photopolymerized dimethacrylate oligomer. J Appl Polym Sci 1991; 42: 2209-22.

[12] Kloosterboer JG, Van De Hei GMM, Gossink RG, Dortant GCM. The effects of volume relaxation and thermal mobilization of trapped radicals on the final conversion of photopolymerized diacrylates. Polymer Commun 1984; 25: 322-25.

[13] Kloosterboer JG, Lijten GFCM. Thermal and mechanical analysis of a photopolymerization process. Polymer 1987; 28: 1149-55.

[14] Egerton PL, Reiser A, Shaw W, Wagner HM. Photoinitiated radical chains in solid polymeric methacrylates. J Polym Sci Polym Chem 1979; 17: 3315-28.

[15] Tryson GR, Shultz AR. A calorimetric study of acrylate photopolymerization. J Polym Sci Polym Phys 1979; 17: 2059-75.

[16] Nicolais L, Apicella A, Grimaldi P. Calorimetric quality control of UV cured optical fiber-coatings. Appl Polym Sci 1987; 33: 2077 86.

[17] Vaidyanathan J, Vaidyanathan TK. Interactive effects of resin composition and ambient temperature of light curing on the percentage conversion, molar heat of cure and hardness of dental composite resins. J Mater Sci Mater Med 1992; 3: 19-27.

[18] Vaidyanathan J, Vaidyanathan TK, Waknine S. In "composite materials for implant applications in the human body: characterization and testing", ASTM STP 1178, ed Jamison RDand Gilbertson LN (American Society for Testing and Materials, Philadelphia, 1993) p. 121.

[19] Emami N, Söderholm KJM, Berglund L. Effect of light power density variation on dental light-cure resin composites. J Dent 2003; 31: 189-96.

[20] Emami N, Söderholm KJM. How light irradiance and curing time affect monomer conversion in light-cured resin composites. Eur J Oral Sci 2003; 111: 1-7.

[21] Ruyter IE, Györösi PP. An infrared spectroscopic study of sealants. Scand J Dent Res 1976; 84: 396-400.

[22] Asmussen E. Factors affecting the quantity of remaining double bonds in restorative resin polymers. Scand J Dent Res 1982; 90: 490-6.

[23] Ruyter IE, Øysæd H. Conversion in different depths of ultraviolet and visible light activated composite materials. Acta Odontol Scand 1982; 40: 179-92.
[24] Eliades GC, Vougiouklakis GJ, Caputo AA. Degree of double bond conversion in light-cured composites. Dent Mater 1987; 3: 19-25.

[25] Ruyter IE, Øysæd H. Composites for use in posterior teeth: composition and conversion. J Biomed Mater Res 1986; 21: 11-23.

[26] Ferracane JL, Greener EH. Fourier Transform infrared analysis of degree of polymerization in unfilled resins-methods comparison. J Dent Res 1984; 63: 1093-5.

[27] Ferracane JL. Correlation between hardness and degree of conversion during the setting reaction of unfilled dental restorative resins. Dent Mater 1985; 1: 11-14.

[28] DeWald JP, Ferracane JL. A comparison of four modes of evaluating depth of cure of light-activated composites. J Dent Res 1987; 66: 727-30.

[29] Chung K, Greener EH. Degree of conversion of seven visible lightcured posterior composites. J Oral Rehab 1988; 15: 555-60.

[30] Rueggeberg FA, Craig RG. Correlation of parameters used to estimate monomer conversion in a light-cured composite. J Dent Res 1988; 67: 932-7.

[31] Rueggeberg FA, Hashinger DT, Fairhurst CW. Calibration of FTIR conversion analysis of contemporary dental resin composites. Dental Mater 1990; 6: 241-9.

[32] Pereira SG, Nunes TG, Kalachandra S. Low viscosity dimethacrylate comonomer compositions [bis-GMA and CH3Bis-GMA]for novel dental composites; analysis of the network by stray-field MRI, solid-state NMR and DSC \& FTIR. Biomater 2002; 23: 3799-806.

[33] Kurdikar DL, Peppas NA. A kinetic-study of diacrylate photopolymerization. Polymer 1994; 35: 1004-11.

[34] Asmussen E, Peutzfeldt A. Influence of UEDMA, BisGMA and TEGDMA on selected mechanical properties of experimental resin composites. Dent Mater 1998; 14: 51-6.

[35] Rueggeberg FA, Jordan DM. Effect of light-tip distance on polymerization of resin composite. Int J Prosthodontic 1993; 6: 364-70.

[36] Emami N, Söderholm KJ. Influence of light-curing procedures and photo-initiator/co-initiator composition on the degree of conversion of light-curing resins. J Mater Sci Mater Med. 2005; 16: 47-52.

[37] Stansbury JW, Dickens SH. Network formation and compositional drift during photo-initiated copolymerization of dimethacrylate monomers. Polymer 2001; 42: 6363-9.

Received: April 01, 2009

Revised: May 21, 2009

Accepted: July 31, 2009

(c) Emami and Söderholm.; Licensee Bentham Open.

This is an open access article licensed under the terms of the Creative Commons Attribution Non-Commercial License (http://creativecommons.org/licenses/by-nc/3.0/) which permits unrestricted, non-commercial use, distribution and reproduction in any medium, provided the work is properly cited. 